\title{
ROVAN, Joseph, Histoire de L'Allemagne des origines à nos jours
}

Pierre Monnet

\section{OpenEdition}

\section{Journals}

Édition électronique

URL : http://journals.openedition.org/ifha/1976

DOI : $10.4000 /$ ifha. 1976

ISSN : 2198-8943

\section{Éditeur}

IFRA - Institut franco-allemand (sciences historiques et sociales)

\section{Référence électronique}

Pierre Monnet, "ROVAN, Joseph, Histoire de L'Allemagne des origines à nos jours », Revue de l'IFHA [En ligne], Date de recension, mis en ligne le 01 janvier 1994, consulté le 22 septembre 2020. URL : http:// journals.openedition.org/ifha/1976 ; DOI : https://doi.org/10.4000/ifha.1976

Ce document a été généré automatiquement le 22 septembre 2020

(CIFHA 


\title{
ROVAN, Joseph, Histoire de L'Allemagne des origines à nos jours
}

\author{
Pierre Monnet
}

C'est à juste titre que ce livre de J.R. paraît dans une collection intitulée »Librairie européenne des idées«. En effet, ce récit des origines et du destin des pays, peuples et Etats allemands arrive au bon moment puisque, depuis l'unification, l'Allemagne contemporaine s'interroge sur son avenir et réfléchit, à la lumière de son passé, sur le sens nouveau qu'elle peut donner au concept de nation. Le lecteur français dispose ainsi désormais d'une synthèse résolument européenne de l'histoire germanique revisitée par un des grands artisans du dialogue franco-allemand.

Mettant précisément à profit sa double culture, J.R. privilégie l'étude des éléments extérieurs qui, depuis le très haut Moyen Age, obligent l'Allemagne à se transformer. Placé depuis le départ sur la route des invasions successives et au cœur exact des échanges entre la Méditerranée chrétienne et latine et le Nord de l'Occident, l'espace germanique devient bientôt le siège d'un Empire précisément chargé de fondre et de synthétiser les apports et les traditions issus de l'une et de l'autre. Tâche immense et souvent contradictoire, qui fixe le destin de ce pays pour longtemps et dans laquelle le religieux tiendra toujours une place essentielle comme l'attestent, entre autres, le combat des deux glaives et plus tard la Réforme cette dernière pouvant être considérée comme l'une des conséquences du premier. On comprend bien de la sorte que cet Empire médiéval ne fut pas seulement un morceau, certes limpide en surface mais baroque en ses profondeurs, de l'histoire allemande mais bien la souche de toute une partie de l'histoire européenne.

Avec la fin du Moyen Age marqué en Allemagne par le rêve universaliste, on assiste à une transformation radicale de l'horizon, mutation qui n'est pas seulement allemande: abaissement de l'Empire (ou de l'Empereur?), crise de l'Eglise mais aussi montée de la papauté, construction de royaumes centralisés et "nationaux" en France et en Angleterre. On peut certes ne pas souscrire entièrement à cette idée de décadence de l'Empire, mais on ne peut que donner raison à J.R. quand il affirme que ce recul n'a pas entraîné un déclin de la nation allemande. C'est au contraire tout l'opposé si l'on songe 
à la Réforme que J.R. qualifie de période la plus émouvante de l'histoire allemande. Car pour l'Allemagne, la Réforme est bien l'épreuve décisive: le feu de l'esprit, la refonte de tous les pays qui la composent, le progrès de la langue et, à terme, l'apprentissage prodigieux du multiconfessionnalisme.

Reprenant à peine ses forces après la paix d'Augsbourg en 1555, l'Empire est bien vite confronté au cataclysme de la Guerre de Trente Ans qui vide ses territoires de plus de $40 \%$ de ses hommes. Mais, à l'instar de la Guerre de Cent Ans pour la France, ce conflit fut aussi l'occasion de la modernité. Que celle-ci ait pris, surtout au tournant des XVIIe et XVIIIe s., un visage prussien n'a pas empêché par ailleurs l'Allemagne de continuer, dans sa diversité politique et religieuse, l'expérience d'un premier "fédéralisme« dont J.R. ne perçoit pas d'équivalent en Europe.

Le choc de la Révolution Française achève de pousser le vieil Empire vers de nouveaux horizons qui, en réponse à l'avancée séculaire de la France vers le Rhin et à sa croisade de la liberté sans frontières, conduisent les Allemands à exalter l'individuel et le mystique dans une notion du Volk dont J.R. suit la fortune jusque dans les ruines de 1945. D'une certaine manière, en 1871 comme en 1933, les IIe et IIIe Reich naissent sous les auspices de la guerre et de la force qui prétendent incarner à leur façon une "révolution" laissant peu de chance à la normalité démocratique de la République de Weimar.

C'est à la lumière de ce tragique XXe s. dont il a directement vécu les douleurs que J.R. livre les pages les plus personnelles et les plus stimulantes sur "son« Allemagne et sa conception de la germanité définie comme »une conversation à deux voix de la rupture et du respect«. L'auteur y puise sa confiance en la capacité actuelle de ce pays à entraîner tout notre continent sur le chemin d'une plus grande liberté. A ce grand objectif, cet ouvrage apporte une contribution forte et convaincante et fait d'autant plus regretter au spécialiste l'absence de bibliographie et de notes.

Pierre MONET 